\title{
Bond Performance of Deep Embedment FRP Bars Epoxy-bonded into Concrete
}

\author{
Manjola Caro ${ }^{\mathrm{a}}$, Yaser Jemaa ${ }^{\mathrm{b}}$, Samir Dirar ${ }^{\mathrm{c}}$, Andrew Quinn ${ }^{\mathrm{d}}$
}

${ }^{a}$ Department of Civil Engineering, University of Birmingham, Edgbaston, Birmingham, B15 2TT, United Kingdom, email: mkc989@bham.ac.uk

${ }^{b}$ Department of Civil Engineering, Liverpool John Moores University, Liverpool, L3 3AF, United Kingdom,email:Y.Jemma@ljmu.ac.uk

${ }^{c}$ Department of Civil Engineering, University of Birmingham, Edgbaston, Birmingham, B15

2TT, United Kingdom,email: s.m.o.h.dirar@bham.ac.uk (corresponding author)

${ }^{d}$ Department of Civil Engineering, University of Birmingham, Edgbaston, Birmingham, B15 2TT, United Kingdom,email: a.d.quinn@bham.ac.uk

ABSTRACT: With increasing numbers of strength-deficient concrete infrastructure assets, strengthening and repair of concrete structures is becoming an issue of international importance. This study examines the bond behaviour of deep embedment (DE) glass fibre reinforced polymer (GFRP) and carbon FRP (CFRP) bars embedded into concrete prisms using an epoxy adhesive. The experimentally investigated parameters were the embedment length, FRP bar type and diameter, concrete compressive strength and hole diameter. The increase in embedded length enhanced the pull-out capacity for both GFRP and CFRP bar types. However, the bond strength and initial stiffness of the bond stress-slip curves decreased with the increase in embedded length. The specimens with DE CFRP bars had higher pull-out capacities and better bond performance than the corresponding specimens with DE GFRP bars. For the specimens with DE CFRP bars, the pull-out capacity increased with the increase in bar diameter and concrete strength but these two parameters did not affect the behaviour of the specimens with DE GFRP bars. The increase in hole diameter reduced the initial stiffness of the specimens with DE GFRP bars but affected neither the failure mode nor the failure loads. For the first time, this paper presents a mathematical 
model for predicting the bond strength of DE FRP bars. The mathematical model was validated against experimental results and demonstrated to produce accurate predictions. It is envisaged that both the mathematical model and the experimental results will contribute to the development of future design guidelines for DE concrete shear strengthening.

Keywords: bond; concrete; deep embedment; epoxy; fibre reinforced polymer; pull-out

\section{INTRODUCTION}

Retrofitting of strength-deficient reinforced concrete (RC) infrastructure assets has become an issue of global significance [1]. Various strengthening techniques utilising fibre reinforced polymer (FRP) composites have been adopted to achieve shear strength enhancement of deficient RC structures [1-8]. Non-corrodible FRP composites can effectively enhance the shear capacity of RC structures due to their high strength-to-weight ratio and durability. A significant advancement in concrete shear strengthening has been the development of the deep embedment (DE) [9-10], or embedded through-section (ETS) [11-12], technique. In this method, vertical or inclined holes are drilled upwards from the soffit in the shear spans of existing RC beams and high viscosity epoxy resin is injected into the drilled holes to bond FRP or steel bars to the concrete core.

Many experimental and numerical studies [9-17] proved the superiority of the DE method over other shear strengthening techniques in terms of the bond performance and shear strengthening effectiveness. For example, Chaallal et al. [11] compared the shear strengthening effectiveness of DE FRP bars, near-surface mounted (NSM) FRP rods and externally bonded (EB) FRP sheets concluding that the shear strength capacity of the strengthened RC beams was increased by $61 \%, 31 \%$ and $23 \%$, respectively. The DE method 
provides higher strengthening effectiveness because, unlike the EB and NSM techniques, in the DE method the concrete core transfers the stresses to the bars. Thus, the DE technique avoids the de-bonding and de-lamination of concrete cover failure mechanisms associated with external shear strengthening techniques [11]. Notwithstanding the above advantages, it can be difficult to drill holes in members with congested internal steel reinforcement. Moreover, DE carbon FRP (CFRP) bars can cause galvanic corrosion if they are in direct contact with existing steel bars. However, this can be addressed by using an electrically insulating epoxy.

Pull-out testing has been commonly adopted as a practical approach to assessing the bond performance for both steel and FRP bars embedded in concrete. Valerio et al. [10] performed sixty-five pull-out tests using aramid FRP (AFRP), glass FRP (GFRP), CFRP and steel bars. These bars were epoxy-bonded using different types of adhesives into $150 \mathrm{~mm} \times 150 \mathrm{~mm} \times$ $150 \mathrm{~mm}$ concrete cubes with a cube compressive strength of $60 \mathrm{MPa}$. Five embedment lengths ranging from 15 to $75 \mathrm{~mm}$ and hole diameters of 1.2 and 1.3 times the bar diameter were considered. Godat et al. [14] performed thirteen pull-out tests on DE CFRP bars. The CFRP bars were epoxy-bonded into concrete blocks with cross-sectional dimensions of 190 $\mathrm{mm} \times 190 \mathrm{~mm}$ and a length of $345 \mathrm{~mm}$. The key studied parameters were embedment length (48 to $285 \mathrm{~mm}$ ) and hole diameter (1.25 to 2 times the bar diameter). The concrete cylinder compressive strength (20.7 and $42.7 \mathrm{MPa}$ ) and bar diameter (9.5 and $12.7 \mathrm{~mm})$ were limitedly considered.

Both research studies $[10,14]$ reported that, for all bar types, the increase in embedded length leads to a higher bonded area and consequently a higher pull-out capacity. Valerio et al. [10] found that the pull-out force values for the DE strengthening combination of non-sag, high 
strength epoxy with steel and CFRP bars were higher than those achieved by the GFRP and AFRP bars. This is due to a better bond performance and a more ductile bond stress-slip response achieved by the steel and CFRP bars which have elastic moduli considerably higher than those of GFRP and AFRP bars. Godat et al. [14] confirmed that the pull-out capacity is higher for FRP bars of greater diameter due to a larger contact area thus higher pull-out force.

An adequate amount of high-viscosity, high-strength epoxy adhesive is crucial to prevent debonding failure and to achieve a good bond between the bar and concrete along its full embedded length. Godat et al. [14] investigated the effect of quantity of adhesive on the bond behaviour of DE CFRP. They recommended an optimum hole diameter of about 1.5 times the bar diameter $\left(1.5 \mathrm{~d}_{\mathrm{b}}\right)$.

Godat et al. [14] reported that as the concrete strength increased, the pull-out capacity also increased and a change in the failure mode of the specimens was also observed. Specimens with low concrete compressive strength (20.7 MPa) failed due to concrete splitting, while specimens with high concrete strength $(42.7 \mathrm{MPa})$ experienced bar pull-out at the bar/adhesive interface.

Nonetheless, the bond behaviour of DE FRP bars is not fully understood. This is reflected in the lack of mathematical models for the bond strength of DE FRP bars. Moreover, except for embedment length, the effect of the main parameters influencing the bond behaviour has so far been limitedly considered. This paper examines the effect of embedment length, bar type and diameter, concrete compressive strength and hole diameter on the bond behaviour of DE FRP bars. Additionally, it presents a mathematical model for the bond strength of DE FRP bars. 


\section{RESEARCH SIGNIFICANCE}

Understanding the FRP-to-concrete bond behaviour is crucial to the safe implementation of the DE shear strengthening technique. For the first time, this paper presents a mathematical model for predicting the bond strength of DE FRP bars. Moreover, this paper investigates the effect of the main parameters influencing the FRP-to-concrete bond behaviour. It is envisaged that both the mathematical model and the experimental results will contribute to the development of future design guidelines for DE concrete shear strengthening.

\section{EXPERIMENTAL PROGRAMME}

The experimental programme is based on the recommendations of CSA/S806-02 [18] as well as the experimental pull-out test studies performed by Valerio et al. [10] and Godat et al. [14]. A total of eighteen concrete cube specimens with embedded GFRP or CFRP bars were tested as reported in Table 1 . The effect of embedment length, bar type and diameter, concrete strength and adhesive quantity on the bond behaviour of the bars was examined. The following sections provide details of the material properties, test specimens, installation of FRP bars and pull-out test setup.

\subsection{Materials}

Two concrete mixes were used. The concrete mixes were designed according to the BRE [19] guidelines. Portland cement (Class 32.5) and aggregates with a maximum size of $10 \mathrm{~mm}$ were used in both concrete mixes. Two batches were used to cast the pull-out specimens with lower concrete strength whereas one batch was used to cast the pull-out specimens with higher concrete strength. Each batch was used to cast six concrete cubes $(200 \mathrm{~mm} \times 200 \mathrm{~mm}$ $\times 200 \mathrm{~mm}$ ) and seven ancillary control specimens (four cubes $(100 \mathrm{~mm} \times 100 \mathrm{~mm} \times 100$ $\mathrm{mm})$ and three cylinders $(100 \mathrm{~mm}$ diameter $\times 200 \mathrm{~mm}$ height $))$. The control specimens were 
used to characterise the concrete compressive strength. The average cylinder compressive strength for each batch on the day of pull-out testing was 26.1 MPa (referred to as C26), 24.8 $\mathrm{MPa}$ (referred to as $\mathrm{C} 25)$ and $45.6 \mathrm{MPa}$ (referred to as $\mathrm{C} 46)$.

Two types of sand-coated FRP bars (CFRP and GFRP) were used in this study. The sandcoated FRP bars had diameters of either $10 \mathrm{~mm}$ or $12 \mathrm{~mm}$. The GFRP bars had an elastic modulus, tensile strength and ultimate strain of $40 \mathrm{GPa}, 973 \mathrm{MPa}$ and $2.43 \%$, respectively, as declared by the manufacturer. The CFRP bars had an elastic modulus, tensile strength and ultimate strain of $130 \mathrm{GPa}, 2300 \mathrm{MPa}$ and $1.76 \%$, respectively, as declared by the manufacturer.

A commercially available high viscosity epoxy resin (Hilti 500) was used to bond the DE FRP bars to the concrete. This epoxy resin had a compressive strength, compressive modulus, tensile strength, bond strength and ultimate strain at failure of $82.7 \mathrm{MPa}, 1493 \mathrm{MPa}, 43.5$ $\mathrm{MPa}, 12.4 \mathrm{MPa}$ and 2\%, respectively, as certified by the manufacturer.

\subsection{Test specimens}

Table 1 provides a summary of the pull-out test specimens. Each specimen had a four-part designation. The first part ( $\mathrm{C} 25, \mathrm{C} 26$ or $\mathrm{C} 46)$ specifies the concrete cylinder compressive strength. The second part identifies the embedded length of the FRP bar $\left(5 d_{b}, 10 d_{b}\right.$ or $15 d_{b}$ where $d_{b}$ is the nominal bar diameter). The third part denotes the FRP bar type and diameter (CFRP $10 / 12$ or GFRP 10/12). The last part represents the hole diameter (either $1.5 \mathrm{~d}_{\mathrm{b}}$ or $1.8 \mathrm{~d}_{\mathrm{b}}$ ). Hence C26-15d $\mathrm{d}$-CFRP12-1.5 $\mathrm{d}_{\mathrm{b}}$ refers to a specimen with a concrete cylinder compressive strength of $26.1 \mathrm{MPa}$, embedment length of $15 \mathrm{~d}_{\mathrm{b}}(180 \mathrm{~mm}), 12 \mathrm{~mm}$ diameter CFRP bar and a central hole with a diameter of $1.5 \mathrm{~d}_{\mathrm{b}}(18 \mathrm{~mm})$. 


\subsection{Installation of FRP bars}

In order to install the CFRP and GFRP bars, vertical holes were cast along the centrelines of the $200 \mathrm{~mm}$ concrete cubes using polyvinyl chloride (PVC) rods with diameters (d) of either $15 \mathrm{~mm}$ or $18 \mathrm{~mm}\left(\mathrm{~d}=\right.$ epoxy thickness $\left.+\mathrm{d}_{\mathrm{b}}\right)$. The PVC rods were positioned vertically at the centres of the moulds prior to concrete casting. To control the embedded length of the FRP bar in a given pull-out specimen, a square $(40 \mathrm{~mm} \times 40 \mathrm{~mm})$ polystyrene block with a central hole equal to the PVC rod diameter acted as a cast-in-concrete bond breaker (see Figure 1). The polystyrene block was glued with waterproof silicon around the PVC rod. The lengths of the polystyrene blocks varied from 10 to $130 \mathrm{~mm}$ depending on the required value of the embedded length. This approach was selected for simplicity and also to prevent any cracking or local damage that may occur if a drilling machine was used. It should be noted that drilling would probably provide a rougher hole surface and consequently improve the bond between the FRP bars and the concrete. De-moulding of all the concrete specimens and the removal of the PVC rods were carried out 24 hours after casting. Following de-moulding, the concrete specimens were marked and cured at room temperature (about $20^{\circ} \mathrm{C}$ ) for at least 28 days.

Before installing the FRP bars, a wire brush was used to roughen the internal surfaces of the holes. This was followed by using compressed air to clean the holes from any cement and aggregate residues. The bottom ends of the holes were blocked to prevent leakage and high viscosity epoxy resin (Hilti 500) was used to fill two-thirds of the holes. A thin layer of epoxy was also applied along the embedded lengths of the FRP bars and then the bars were twisted as they were being inserted vertically into the holes. This step was deemed necessary in order to ensure that no air pockets were formed or left inside the holes. The excess epoxy was removed from the top surfaces of the holes. The specimens were then cured for a week at room temperature (about $20^{\circ} \mathrm{C}$ ) before testing. Of note is that this installation technique was 
used by Jemaa et al. [15] to strengthen large scale deficient RC beams using GFRP bars and epoxy adhesive similar to those reported in this study. The technique resulted in $96 \%$ shear strength enhancement and GFRP strain of up to $0.91 \%$.

\subsection{Test setup}

Figure 1 illustrates the pull-out test setup. The FRP bars were cut into $700 \mathrm{~mm}$ lengths to meet the recommendations of Godat et al. [14] and to ensure that the test specimens fitted properly within the testing machine. The concrete cube, together with the DE FRP bar, was

placed inside a steel box as shown in Figure 1. To ensure that the FRP bar remained undamaged during testing, a $310 \mathrm{~mm}$ long hollow steel tube with $42 \mathrm{~mm}$ external diameter and $4.8 \mathrm{~mm}$ wall thickness was bonded to the upper end of the FRP bar using Hilti 500 epoxy resin. The steel tube surrounding the FRP bar was then gripped by the testing machine.

Linear variable differential transducers (LVDTs) were mounted on a PVC rig to measure the slip between the FRP bar and the concrete cube at the loaded end. A displacement-controlled testing machine was used to apply the pull-out force at a rate of $0.03 \mathrm{~mm} / \mathrm{s}$. This arrangement is similar to that used by Godat et al. [10].

\section{EXPERIMENTAL RESULTS}

Table 2 gives the peak pull-out force (i.e. pull-out capacity), maximum average bond stress, slip at peak pull-out force and failure mode for each tested specimen. Based on ACI 440.1R06 [20], the average bond stress $(\tau)$ is given by:

$$
\tau=\frac{P}{\pi d_{b} l_{b}}
$$


where $\mathrm{P}$ is the pull-out force, $\mathrm{d}_{\mathrm{b}}$ is the bar diameter and $\mathrm{l}_{\mathrm{b}}$ is the embedded length of the bar. Equation 1 assumes the average bond stress to be constant along the embedded length. Although this assumption is not fully accurate due to the non-uniform variation of bond stresses along the embedded length [14, 21-23], the concept of average bond stress is used in this study as it facilitates comparison of results.

\subsection{Failure modes}

One specimen, C26-15d $\mathrm{d}_{\mathrm{b}}$-CFRP12-1.5 $\mathrm{d}_{\mathrm{b}}$, failed due to concrete splitting. This failure mode involved a crack plane that crossed the central hole and split the concrete cube into two parts (see Figure 2a). This failure mode was sudden and brittle due to the tensile failure of the concrete. Except for C26-15d $\mathrm{d}_{\mathrm{b}}-\mathrm{CFRP} 10-1.5 \mathrm{~d}_{\mathrm{b}}$ and C46-15d $\mathrm{d}_{\mathrm{b}}-\mathrm{CFRP} 10-1.5 \mathrm{~d}_{\mathrm{b}}$, the mode of failure for the remaining specimens with an embedded length of $15 \mathrm{~d}_{\mathrm{b}}$ was bar rupture (see Figure $2 b$ ). The FRP bars remained well attached to the concrete cubes, with no visible cracks, until the end of testing. C26-15d $\mathrm{d}_{\mathrm{b}}-\mathrm{CFRP} 10-1.5 \mathrm{~d}_{\mathrm{b}}, \mathrm{C} 46-15 \mathrm{~d}_{\mathrm{b}}-\mathrm{CFRP} 10-1.5 \mathrm{~d}_{\mathrm{b}}$ and the specimens with shorter embedded lengths $\left(5 \mathrm{~d}_{\mathrm{b}}\right.$ and $\left.10 \mathrm{~d}_{\mathrm{b}}\right)$ experienced pull-out at the adhesive/concrete interface (see Figure 2c). A thin adhesive layer was attached to the FRP bars at failure. These results confirm previous findings $[10,14]$ suggesting that the increase in embedment length eventually leads to tensile failure of the bar.

Three sets of specimens were tested twice to examine repeatability of the results. The first set of specimens, C26-15d $\mathrm{d}_{\mathrm{b}}$-GFRP12-1.5 $\mathrm{d}_{\mathrm{b}}$, failed due to rupture of the GFRP bar (see Figure 2b). The difference in pull-out force at failure was $13.1 \mathrm{kN}(21.2 \%)$ and might be attributable to unintended bending effects. The second set of duplicate specimens, C25-5d $\mathrm{d}_{\mathrm{b}}$-GFRP12$1.5 \mathrm{~d}_{\mathrm{b}}$, failed due to bar pull-out (slip) at the adhesive/concrete interface. The difference in peak pull-out force and maximum average bond stress were $4.3 \mathrm{kN}(15.9 \%)$ and $1.9 \mathrm{MPa}$ 
(15.9\%), respectively. The third set of duplicate specimens, C25-5d $\mathrm{d}_{\mathrm{b}}-\mathrm{CFRP} 12-1.5 \mathrm{~d}_{\mathrm{b}}$, experienced bar pull-out without developing cracks in the concrete (see Figure 2c). The difference in peak pull-out force and maximum average bond stress were $1.5 \mathrm{kN}(4.8 \%)$ and $0.7 \mathrm{MPa}(4.8 \%)$, respectively. Of note is that each set of duplicate specimens had comparable initial stiffness values.

Specimen C46-15d $\mathrm{d}_{\mathrm{b}}-\mathrm{CFRP} 10-1.5 \mathrm{~d}_{\mathrm{b}}$ is comparable to specimen C2-1.5d-9.5S-15d tested by Godat et al. [14]. The former specimen, which had cast-in-concrete holes, failed due to bar pull-out at a force of $74.8 \mathrm{kN}$ whereas the latter specimen, which had drilled holes, failed due to bar pull-out at a force of $91.2 \mathrm{kN}$. This result suggests that the bond strength of the specimens with cast-in-concrete holes is about $82 \%$ of that of the specimens with drilled holes.

\subsection{Stiffness of the bond-slip curves}

Figures $3 \mathrm{a}$ and $3 \mathrm{~b}$ illustrate the pull-out force-slip and average bond stress-slip curves for the specimens with $12 \mathrm{~mm}$ FRP bars, respectively. The corresponding curves for the specimens with $10 \mathrm{~mm}$ FRP bars are presented in Figures $4 \mathrm{a}$ and 4b, respectively. It should be noted that both Figures 3 and 4 give the global bond behaviour which is characterised by the pull-out force (or average bond stress) and the slip at the loaded end. On the other hand, the local bond behaviour defines the FRP/concrete interaction at a sectional level and is characterised by the interfacial bond stress at a given section and the corresponding interfacial slip at the same section. The global behaviour can therefore be thought of as summing up the local response along the bonded length. 
Two types of behaviour can be seen in Figures 3 and 4. The majority of specimens that experienced pull-out failure had a behaviour that is characterised by an initial, almost linear, increase in the pull-out force or average bond stress with slip (ascending branch), followed by a gradually descending branch once the maximum pull-out force or average bond stress is achieved. On the other hand, the specimens that failed due to bar rupture had similar initial response to those specimens which failed due to pull-out. However, there was a sudden drop at the peak load caused by the brittle failure of the FRP bars.

The effect of embedded length on the initial stiffness (i.e. the stiffness of the ascending branch) of the bond stress-slip curves can be seen in Figures $3 \mathrm{~b}$ and $4 \mathrm{~b}$. As the embedment length increased from $5 \mathrm{~d}_{\mathrm{b}}$ to $15 \mathrm{~d}_{\mathrm{b}}$, the initial stiffness of the average bond stress-slip curves was reduced. As a result, the slip values corresponding to the maximum average bond stresses increased with increasing the embedded length for both bar types. The highest slip values corresponding to the maximum average bond stresses were obtained by the FRP bars with an embedment length of $15 \mathrm{~d}_{\mathrm{b}}$.

As can be observed in Figures 3 and 4, the specimens with CFRP bars had higher initial stiffness than the corresponding specimens with GFRP bars. The higher stiffness for the specimens with CFRP bars was to be expected as the elastic modulus of the CFRP bars is higher than that of the GFRP bars. As a result, the slip values corresponding to the peak pullout forces (see Figures $3 \mathrm{a}$ and $4 \mathrm{a}$ ) and the slips values corresponding to the maximum average bond stresses (see Figures $3 \mathrm{~b}$ and $4 \mathrm{~b}$ ) were lower for the specimens with CFRP bars; while the maximum bond stresses were higher for these specimens confirming a better bond performance. 
The concrete compressive strength did not have a significant impact on the initial stiffness of the specimens with GFRP bars. As can be seen in Figures $4 a$ and $4 b, C 26-15 d_{b}-$ GFRP10$1.5 \mathrm{~d}_{\mathrm{b}}$ and C46-15d $\mathrm{d}_{\mathrm{b}}$-GFRP10-1.5 $\mathrm{d}_{\mathrm{b}}$, which differed in concrete strength only, had approximately equal initial stiffness. C26-15d $\mathrm{d}_{\mathrm{b}}$-CFRP10-1.5 $\mathrm{d}_{\mathrm{b}}$ had higher initial stiffness than that of C46-15d $d_{b}$ CFRP10-1.5d although the latter specimen had higher concrete compressive strength. Premature cracking (e.g. due to shrinkage) could have resulted in the lower stiffness of C46-15d $\mathrm{d}_{\mathrm{b}}$-CFRP10-1.5 $\mathrm{d}_{\mathrm{b}}$. Further testing is required to confirm this result.

The increase in hole diameter from $1.5 \mathrm{~d}_{\mathrm{b}}$ to $1.8 \mathrm{~d}_{\mathrm{b}}$ resulted in a reduction in the initial stiffness of C26-15d $\mathrm{d}_{\mathrm{b}}$-GFRP10-1.8d $\mathrm{d}_{\mathrm{b}}$ compared to that of C26-15d $\mathrm{d}_{\mathrm{b}}-\mathrm{GFRP} 10-1.5 \mathrm{~d}_{\mathrm{b}}$ (see Figures $4 \mathrm{a}$ and $4 \mathrm{~b}$ ). C26-15d $\mathrm{d}_{\mathrm{b}}$-GFRP10-1.8d $\mathrm{d}_{\mathrm{b}}$ had the lowest initial stiffness suggesting that the combination of GFRP bars and a higher quantity of adhesive (i.e. larger hole diameter) has a detrimental effect on stiffness. Yet, the mode of failure was not affected by the increase in quantity of adhesive as both specimens experienced rupture of the GFRP bars.

\subsection{Effect of embedment length}

Table 2 shows that the pull-out capacity increased with the increase in embedded length. An increase of two times (from $5 \mathrm{~d}_{\mathrm{b}}$ to $10 \mathrm{~d}_{\mathrm{b}}$ ) in the embedded length led to increases of $46 \%$ and $61 \%$ in the pull-out capacity of the $12 \mathrm{~mm}$ GFRP and CFRP specimens with a concrete compressive strength of $24.8 \mathrm{MPa}$, respectively. The corresponding increases for the specimens with a concrete compressive strength of $45.6 \mathrm{MPa}$ and $10 \mathrm{~mm}$ GFRP or CFRP bars were $87 \%$ and $106 \%$, respectively.

Figure 5 combines the results of this study with the results of Valerio et al. [10] and Godat et al. [14]. Except for the few pull-out specimens with a concrete compressive strength of 45.6 
MPa, Figure 5 shows that the maximum average bond stress generally decreased with the increase in embedded length, which is in agreement with Equation 1. An increase of two times (from $5 d_{b}$ to $10 d_{b}$ ) in the embedded length led to decreases of about $28 \%$ and $20 \%$ in the maximum average bond stresses of the $12 \mathrm{~mm}$ GFRP and CFRP specimens with a concrete compressive strength of $24.8 \mathrm{MPa}$, respectively. This trend is further highlighted by the results of Valerio et al. [10] and Godat et al. [14] which show that increases of five and six times, respectively, in the embedded length led to decreases of almost 1.5 and 2 times, respectively, in the maximum average bond stress.

The results of this study combined with those of Valerio et al. [10] show that, at given embedded length and concrete strength values, the specimens with CFRP bars had generally higher bond strength values than the corresponding specimens with GFRP bars (see Figure 5). This result may be explained by the better bond performance of the CFRP bars which have higher elastic modulus than that of the GFRP bars. Of note is that Godat et al. [14] did not test GFRP pull-out specimens.

\subsection{Effect of bar diameter}

The impact of bar diameter on pull-out and bond strengths can be inferred from specimens C26-15d $\mathrm{d}_{\mathrm{b}}$-CFRP12-1.5 $\mathrm{d}_{\mathrm{b}}$ and C26-15d $\mathrm{d}_{\mathrm{b}}$-CFRP10-1.5 $\mathrm{d}_{\mathrm{b}}$ (see Table 2). The corresponding specimens with GFRP bars failed due to bar rupture; so both their failure mode and failure loads were not affected by the change in bar diameter. The increase in bar diameter from 10 to $12 \mathrm{~mm}$ resulted in a $17.1 \mathrm{kN}(30.4 \%)$ increase in the pull-out capacity for the tested specimens with DE CFRP bars. For a larger bar diameter, the greater bond area results in a higher pull-out capacity [14]. In contrast, the maximum average bond stress decreased by 1.1 
MPa (9.2\%). This decrease may be explained by the higher amount of elastic energy available when using large diameter bars [14, 22].

\subsection{Effect of concrete compressive strength}

The effect of concrete compressive strength on pull-out capacity and maximum average bond stress can be inferred from specimens C26-15d $\mathrm{d}_{\mathrm{b}}$-CFRP10-1.5 $\mathrm{d}_{\mathrm{b}}$ and C46-15d $\mathrm{d}_{\mathrm{b}}$-CFRP10-1.5d (see Table 2). The corresponding specimens with GFRP bars failed due to bar rupture; so both their failure mode and failure loads were not affected by the change in concrete compressive strength. As the concrete strength increased from 26.1 to $45.6 \mathrm{MPa}$, the pull-out capacity increased by $18.6 \mathrm{kN}(33 \%)$. C26-15d $\mathrm{d}_{\mathrm{b}}-\mathrm{CFRP} 10-1.5 \mathrm{~d}_{\mathrm{b}}$ and C46-15d $\mathrm{d}_{\mathrm{b}}-\mathrm{CFRP} 10-1.5 \mathrm{~d}_{\mathrm{b}}$ had the same bar diameter and embedment length and thus the maximum average bond stress increased by $4 \mathrm{MPa}(33 \%)$ due to the increase in concrete strength. The pull-out force induces shear stresses along the DE FRP bar. Pull-out (bond) failure occurs when the applied interfacial stresses exceed the resistance of the FRP-to-concrete interface [21]. Increasing the concrete compressive strength increases the resistance of the FRP-to-concrete interface. This, in turn, enhances the bond strength.

\subsection{Effect of hole diameter}

The two specimens with different hole diameters (C26-15d $\mathrm{d}_{\mathrm{b}}$-GFRP10-1.5 $\mathrm{d}_{\mathrm{b}}$ and C26-15d $\mathrm{d}_{\mathrm{b}^{-}}$ GFRP10-1.8d $\mathrm{d}_{\mathrm{b}}$ ) failed due to bar rupture at $58.2 \mathrm{kN}$ and $54.7 \mathrm{kN}$, respectively. Hence it can only be inferred that the increase in hole diameter from $15 \mathrm{~mm}$ to $18 \mathrm{~mm}$ affected neither the failure mode nor the tensile capacity of the GFRP bars. Godat et al. [14] investigated the effect of three hole diameters $\left(1.25 \mathrm{~d}_{\mathrm{b}}(12 \mathrm{~mm}), 1.5 \mathrm{~d}_{\mathrm{b}}(15 \mathrm{~mm})\right.$ and $\left.2.0 \mathrm{~d}_{\mathrm{b}}(19 \mathrm{~mm})\right)$. The three tested specimens failed due to bar pull-out. They reported that increasing the hole diameter from $1.25 \mathrm{~d}_{\mathrm{b}}$ to $1.5 \mathrm{~d}_{\mathrm{b}}$ increased the pull-out capacity by $10.8 \mathrm{kN}(13.4 \%)$ whereas the further 
increase in hole diameter to $2.0 \mathrm{~d}_{\mathrm{b}}$ decreased the pull-out capacity by $12.5 \mathrm{kN}(13.9 \%)$. They argued that the increase in hole diameter to $1.5 \mathrm{~d}_{\mathrm{b}}$ improved bonding while maintaining a greater confinement whereas the further increase to $2.0 \mathrm{~d}_{\mathrm{b}}$ reduced the effect of confinement [14]. However, this latter effect was not observed for the specimens with DE GFRP bars tested in this study as explained above.

\section{MATHEMATICAL MODELLING}

Currently, there are no published mathematical models for predicting the bond strength of DE FRP bars. The Concrete Society Technical Report 55 (TR55) [23] suggests that the bond strength of DE FRP bars may be taken as $15 \mathrm{MPa}$ in the absence of test data. Mofidi et al. [12] proposed the bond strength values of $21.3 \mathrm{MPa}$ and $8.4 \mathrm{MPa}$ for plain and sand-coated FRP bars, respectively. However, the experimental results clearly demonstrate that the bond behaviour of DE FRP bars is so complex that the bond strength cannot be represented by a single fixed value.

This paper proposes a new model for the bond strength of DE FRP bars. The form of the mathematical model chosen is given by:

$$
\tau=\alpha f_{c}^{j} l_{b}^{k} d_{b}^{m} E^{n} E_{p}^{r}
$$

where $\tau$ is the average bond strength; $f_{c}$ is the concrete cylinder compressive strength; $l_{b}, d_{b}$ and $\mathrm{E}$ are the embedded length, bar diameter and elastic modulus of the DE FRP bar, respectively; and $\mathrm{E}_{\mathrm{p}}$ is the elastic modulus of the adhesive. The key advantage of the proposed model is that it explicitly takes into account the constituent parameters influencing the bond 
behaviour, thus permitting variations during the design process. The role of such a mathematical model is crucial for developing shear strengthening design guidelines.

In the calibration process, data were restricted to experiments where bar pullout failure occurred. The model was calibrated using a multiple linear regression on two sets of data (11 experimental tests from this research study and 9 tests by Godat et al.[14]) which suggest parameter values of: $\mathrm{j}=0.31 \pm 0.18, \mathrm{k}=-0.32 \pm 0.05, \mathrm{~m}=-0.59 \pm 0.59, \mathrm{n}=0.23 \pm 0.05$ and $\mathrm{r}$ $=0.52 \pm 0.1$. The suggested value of $\alpha$ is $\exp (-0.52)=0.59$ but the uncertainty of this is large $(-0.52 \pm 2.4$ in the exponent), possibly because of factors (e.g. roughness of the adhesive-toconcrete interface) which have not been included in the model. The large uncertainly of the $\mathrm{m}$ value is probably related to the small range of diameters and thus contact surface areas considered. Additional tests need to be conducted considering a larger range of bar diameters and other parameters. The proposed model may be written as:

$$
\tau=0.59 f_{c}^{0.31} l_{b}^{-0.32} d_{b}^{-0.59} E^{0.23} E_{p}^{0.52}
$$

In terms of statistical probability, elastic modulus of the epoxy adhesive, elastic modulus of the bar and embedded length are all highly significant ( $\mathrm{p}$-value $<0.001)$ whereas concrete compressive strength and bar diameter are less significant. The justification for including these parameters in the model is therefore theoretical rather than statistical and further work is required to improve the values associated with these parameters. In addition, as the selected data were restricted only to bar pullout failure mode, the impact of concrete strength is not significant (or does not play a significant role) as long as the compressive strength of concrete is sufficient to achieve the bond strength between the concrete and DE FRP bar. In 
comparison between predicted and measured values (see Figure 6), the typical error of the proposed model is $\pm 2 \%$ and the standard error is $\pm 9 \%$.

The proposed model was validated against the results of nineteen pull-out specimens tested by Valerio et al. [10]. These specimens were selected from a larger database of 65 specimens on the basis of bar material, epoxy adhesive and failure mode. Only the specimens with AFRP, GFRP or CFRP bars bonded into concrete using a high viscosity adhesive were deemed adequate for validation purposes. The remaining specimens with steel bars and/or low viscosity adhesive are beyond the scope of the proposed model. It should be noted that a low viscosity adhesive is unsuitable for DE strengthening applications and will negatively impact the bond performance [14]. The nineteen specimens chosen for validation purposes had embedment lengths ranging from 15 to $75 \mathrm{~mm}$ and hole diameters of 1.2 or 1.3 times the bar diameter. All the selected specimens experienced bar pullout failure mode only.

Figure 7 displays the comparison between the predicted and experimental bond strength values for fourteen specimens with CFRP/GFRP bars and five specimens with AFRP bars. It must be noted that for the same bar diameter and embedded length, the experimental bond strength values achieved by CFRP bars were almost twice as those achieved by AFRP bars. This different bond performance of AFRP bars suggests a smaller alpha coefficitient $(\alpha=0.5$ $\times 0.59=0.295)$ be adopted for the proposed bond strength model (Equation 2) which led to more accurate predictions.

It can be seen in Figure 7 that the proposed model predicted well the results of Valerio et al. [10] tests. In comparison between predicted and measured values, the typical error of the proposed model for this data set is $\pm 2 \%$ and the standard error is $\pm 18 \%$. The predictions 
were more accurate for CFRP/GFRP bars compared to AFRP bars but this can be addressed through a change to the alpha value used in the model. Additional tests need to be conducted using AFRP bars to assess the consistency of results and their bond performance.

\section{CONCLUSIONS}

This research study has expanded the experimental results and has provided further insight into the bond performance of DE FRP bars by conducting pull-out tests on both CFRP and GFRP bars epoxy-bonded into $200 \mathrm{~mm} \times 200 \mathrm{~mm} \times 200 \mathrm{~mm}$ concrete cubes. The impact of embedment length, bar type and diameter, concrete strength and hole diameter on the bond behaviour was examined. Based on the results of this study, the following conclusions can be made:

- The increase in embedded length enhanced the pull-out capacity but reduced both the maximum average bond stress and the initial stiffness of the bond stress-slip curves. The GFRP bars with embedded lengths of $15 d_{b}$ failed by rupture whereas the GFRP bars with shorter embedded lengths $\left(5 d_{b}\right.$ and $\left.10 d_{b}\right)$ failed due to bar pull-out. Except for one specimen which failed due to concrete splitting, the CFRP bars failed due to bar pull-out.

- The specimens with CFRP bars had higher pull-out and bond strengths as well as higher initial bond-slip stiffness than the corresponding specimens with GFRP bars. The slip values corresponding to both the peak pull-out forces and the maximum average bond stresses were lower while the average bond stresses were higher for the specimens with CFRP bars, confirming a better bond performance.

- The increase in bar diameter from 10 to $12 \mathrm{~mm}$ led to a $30.4 \%$ increase in the pull-out capacity and 9.2\% decrease in the maximum average bond stress for the specimens with DE CFRP bars. The behaviour of the corresponding specimens with DE GFRP bars was not affected by the change in bar diameter and these specimens failed due to bar rupture. 
- The increase in concrete compressive strength from 26.1 to $45.6 \mathrm{MPa}$ increased both the pull-out capacity and the maximum average bond stress for the specimens with DE CFRP bars by about $33 \%$. The concrete compressive strength did not have a significant impact on the initial stiffness, pull-out capacity or failure mode of the specimens with DE GFRP bars.

- The increase in hole diameter from $1.5 \mathrm{~d}_{\mathrm{b}}$ to $1.8 \mathrm{~d}_{\mathrm{b}}$ reduced the initial stiffness of the specimens with DE GFRP bars but affected neither the failure mode (bar rupture) nor the failure loads.

- A new mathematical model was proposed to predict the bond strength of DE FRP bars epoxy-bonded into concrete. The model was validated against experimental results and was demonstrated to produce accurate predictions.

\section{ACKNOWLEDGEMENTS}

The financial support of the Engineering and Physical Sciences Research Council (EPSRC) through Grant EP/L010364/1 is gratefully acknowledged. The authors are grateful to the staff of the Civil Engineering Laboratory at the University of Birmingham for their help and

support. Additional data related to this publication is available at http://rab.bham.ac.uk/pubs.asp?id=4ccd20dd-3ef8-4db1-8e37-1e3169fce306 or may be accessed via http://findit.bham.ac.uk.

\section{REFERENCES}

[1] Dirar S, Lees J and Morley C (2013) Precracked reinforced concrete T-beams repaired in shear with bonded carbon fiber-reinforced polymer sheets. ACI Structural Journal 109(2): 215-24.

[2] Rahal KN and Rumaih HA (2011) Tests on reinforced concrete beams strengthened in shear using near surface mounted CFRP and steel bars. Engineering Structures 33: 53-62. 
[3] Qin S, Dirar S, Yang J, Chan AHC and Elshafie M (2015) CFRP shear strengthening of reinforced-concrete T-beams with corroded shear links. ASCE Journal of Composites for Construction 19(5): 04014081.

[4] Dirar S, Lees JM and Morley CT (2013) Precracked reinforced concrete T-beams repaired in shear with prestressed carbon fiber-reinforced polymer straps. ACI Structural Journal 110(5): 855-66.

[5] Triantafillou TC (1998) Shear strengthening of reinforced concrete beams using epoxybonded FRP composites. ACI Structural Journal 95(2): 107-115.

[6] Bousselham A and Chaallal O (2008) Mechanisms of shear resistance of concrete beams strengthened in shear with externally bonded FRP. ASCE Journal of Composite Construction 12(5): 499-512.

[7] De Lorenzis L and Nanni A (2001) Shear strengthening of reinforced concrete beams with near-surface mounted fiber-reinforced polymer rods. ACI Structural Journal 98(1): 60-68.

[8] Rizzo A and De Lorenzis L (2009) Behavior and capacity of RC beams strengthened in shear with NSM FRP reinforcement. Construction and Building Materials 23(4): 15551567.

[9] Valerio P and Ibell TJ (2003) Shear strengthening of existing concrete bridges. Structures and Buildings 156(1): 75-84.

[10] Valerio P, Ibell TJ and Darby AP (2009) Deep embedment of FRP for concrete shear strengthening. Structures and Buildings 162(5): 311-21.

[11] Chaallal O, Mofidi A, Benmokrane B and Neale K (2011) Embedded through-section FRP rod method for shear strengthening of RC beams: performance and comparison with existing techniques. ASCE Journal of Composites for Construction 15(3): 374-83. 
[12] Mofidi A, Chaallal O, Benmokrane B and Neale K (2012) Experimental tests and design model for RC beams strengthened in shear using the embedded through-section FRP method. ASCE Journal of Composites for Construction 16(5): 540-50.

[13] Breveglieri M, Aprile A and Barros JAO (2015) Embedded Through-Section shear strengthening technique using steel and CFRP bars in RC beams of different percentage of existing stirrups. Composite Structures 126: 101-13.

[14] Godat A, L'Hady A, Chaallal O and Neale KW (2012) Bond behavior of the ETS FRP bar shear-strengthening method. ASCE Journal of Composites for Construction 16(5): 529-39.

[15] Jemaa Y, Jones C and Dirar S (2015) Deep Embedment strengthening of full-scale shear deficient concrete beams. Proceedings of the $12^{\text {th }}$ International Symposium on Fiber Reinforced Polymers for Reinforced Concrete Structures (FRPRCS-12) and the $5^{\text {th }}$ AsiaPacific Conference on Fiber Reinforced Polymers in Structures (APFIS-2015) Joint Conference. International Institute for FRP in Construction (IIFC), Nanjing, China. 6pp.

[16] Breveglieri M, Aprile A and Barros JAO (2016) RC beams strengthened in shear using the Embedded Through-Section technique: Experimental results and analytical formulation. Composites Part B 89: 266-281.

[17] Qapo M, Dirar S and Jemaa Y (2016) Finite element parametric study of reinforced concrete beams shear-strengthened with embedded FRP bars. Composite Structures 149: 93-105.

[18] Canadian Standards Association (2007) Design and construction of building components with fiber-reinforced polymers. Report No. CAN/CSA-S806-02, Rexdale, Canada, 177pp.

[19] Teychenné DC, Franklin RE and Erntroy HC (1997) Design of normal concrete mixes. Building Research Establishment Ltd, Garston, Watford, WD2 7JR, United Kingdom. 
[20] American Concrete Institute (2006) Guide for the design and construction of structural concrete reinforced with FRP bars. Report No. 440 1R-06, Farmington Hills, MI, 44pp.

[21] Tepfers R and De Lorenzis L (2003) Bond of FRP reinforcement in concrete - a challenge. Mechanics of Composite Materials 39(4): 315-32.

[22] Baena M, Torres L, Turon A and Barris C (2009) Experimental study of bond behaviour between concrete and FRP bars using a pull-out test. Composites Part B: Engineering 40(8): 784-79.

[23] The Concrete Society (2012) Design guidance for strengthening concrete structures using fibre composite materials. Technical Report 55 (TR55), Camberley, United Kingdom, 187pp. 
Table 1 - Test specimens

\begin{tabular}{|c|c|c|c|c|c|}
\hline Specimen & $\begin{array}{l}\text { Concrete } \\
\text { compressive } \\
\text { strength } \\
(\mathrm{MPa}) \\
\end{array}$ & $\begin{array}{l}\text { Bar } \\
\text { type }\end{array}$ & $\begin{array}{c}\text { Bar } \\
\text { diameter } \\
(\mathrm{mm})\end{array}$ & $\begin{array}{l}\text { Embedded } \\
\text { length } \\
(\mathrm{mm})\end{array}$ & $\begin{array}{c}\text { Hole } \\
\text { diameter } \\
(\mathrm{mm})\end{array}$ \\
\hline C26-15d $\mathrm{d}_{\mathrm{b}}$-CFRP12-1.5d $\mathrm{d}_{\mathrm{b}}$ & 26.1 & CFRP & 12 & $180\left(15 d_{b}\right)$ & $18\left(1.5 d_{b}\right)$ \\
\hline C $26-15 d_{b}-$ GFRP12-1.5 $d_{b}{ }^{1}$ & 26.1 & GFRP & 12 & $180\left(15 d_{b}\right)$ & $18\left(1.5 \mathrm{~d}_{\mathrm{b}}\right)$ \\
\hline C26-15d $\mathrm{d}_{\mathrm{b}}$-GFRP12-1.5d $\mathrm{d}_{\mathrm{b}}{ }^{1}$ & 26.1 & GFRP & 12 & $180\left(15 d_{b}\right)$ & $18\left(1.5 \mathrm{~d}_{\mathrm{b}}\right)$ \\
\hline C26-15d $\mathrm{d}_{\mathrm{b}}-\mathrm{GFRP} 10-1.5 \mathrm{~d}_{\mathrm{b}}$ & 26.1 & GFRP & 10 & $150\left(15 d_{b}\right)$ & $15\left(1.5 \mathrm{~d}_{\mathrm{b}}\right)$ \\
\hline C26-15d $\mathrm{d}_{\mathrm{b}}$-GFRP10-1.8d & 26.1 & GFRP & 10 & $150\left(15 d_{b}\right)$ & $18\left(1.8 \mathrm{~d}_{\mathrm{b}}\right)$ \\
\hline C $26-15 d_{b}-C F R P 10-1.5 d_{b}$ & 26.1 & CFRP & 10 & $150\left(15 d_{b}\right)$ & $15\left(1.5 \mathrm{~d}_{\mathrm{b}}\right)$ \\
\hline C25-10d $\mathrm{d}_{\mathrm{b}}$-GFRP12-1.5d & 24.8 & GFRP & 12 & $120\left(10 d_{b}\right)$ & $18\left(1.5 \mathrm{~d}_{\mathrm{b}}\right)$ \\
\hline C $25-10 d_{b}-C F R P 12-1.5 d_{b}$ & 24.8 & CFRP & 12 & $120\left(10 d_{b}\right)$ & $18\left(1.5 \mathrm{~d}_{\mathrm{b}}\right)$ \\
\hline C25-5d $d_{b}-$ GFRP12-1.5 $d_{b}^{2}$ & 24.8 & GFRP & 12 & $60\left(5 d_{b}\right)$ & $18\left(1.5 \mathrm{~d}_{\mathrm{b}}\right)$ \\
\hline C $25-5 d_{b}-$ GFRP12-1.5d ${ }_{b}^{2}$ & 24.8 & GFRP & 12 & $60\left(5 d_{b}\right)$ & $18\left(1.5 \mathrm{~d}_{\mathrm{b}}\right)$ \\
\hline C25-5d $d_{b}$-CFRP12-1.5d ${ }_{b}^{3}$ & 24.8 & CFRP & 12 & $60\left(5 d_{b}\right)$ & $18\left(1.5 \mathrm{~d}_{\mathrm{b}}\right)$ \\
\hline C $25-5 d_{b}-C F R P 12-1.5 d_{b}{ }^{3}$ & 24.8 & CFRP & 12 & $60\left(5 d_{b}\right)$ & $18\left(1.5 \mathrm{~d}_{\mathrm{b}}\right)$ \\
\hline C46-15d $\mathrm{d}_{\mathrm{b}}$-GFRP10-1.5d & 45.6 & GFRP & 10 & $150\left(15 d_{b}\right)$ & $15\left(1.5 \mathrm{~d}_{\mathrm{b}}\right)$ \\
\hline C $46-15 d_{b}-C F R P 10-1.5 d_{b}$ & 45.6 & CFRP & 10 & $150\left(15 d_{b}\right)$ & $15\left(1.5 \mathrm{~d}_{\mathrm{b}}\right)$ \\
\hline C46-10d $\mathrm{d}_{\mathrm{b}}$-GFRP10-1.5d & 45.6 & GFRP & 10 & $100\left(10 d_{b}\right)$ & $15\left(1.5 \mathrm{~d}_{\mathrm{b}}\right)$ \\
\hline C $46-10 d_{b}-C F R P 10-1.5 d_{b}$ & 45.6 & CFRP & 10 & $100\left(10 d_{b}\right)$ & $15\left(1.5 \mathrm{~d}_{\mathrm{b}}\right)$ \\
\hline C46-5d $d_{b}$-GFRP10-1.5d $d_{b}$ & 45.6 & GFRP & 10 & $50\left(5 d_{b}\right)$ & $15\left(1.5 \mathrm{~d}_{\mathrm{b}}\right)$ \\
\hline C46-5d $\mathrm{d}_{\mathrm{b}}-\mathrm{CFRP} 10-1.5 \mathrm{~d}_{\mathrm{b}}$ & 45.6 & CFRP & 10 & $50\left(5 d_{b}\right)$ & $15\left(1.5 \mathrm{~d}_{\mathrm{b}}\right)$ \\
\hline $1,2,3$ Repeated specimens & & & & & \\
\hline
\end{tabular}


Table 2 - Test results

\begin{tabular}{|c|c|c|c|c|}
\hline Specimen & $\begin{array}{l}\text { Peak } \\
\text { pull-out } \\
\text { force } \\
(\mathrm{kN})\end{array}$ & $\begin{array}{c}\text { Maximum } \\
\text { average } \\
\text { bond stress } \\
(\mathrm{MPa})\end{array}$ & $\begin{array}{c}\text { Slip at } \\
\text { peak pull- } \\
\text { out force } \\
(\mathrm{mm})\end{array}$ & Failure mode \\
\hline C26-15d $d_{b}-$ CFRP12-1.5 d & 73.3 & 10.8 & 3.2 & Concrete splitting \\
\hline C26-15d $\mathrm{d}_{\mathrm{b}}$-GFRP12-1.5d $\mathrm{d}_{\mathrm{b}}{ }^{1}$ & 61.9 & 9.1 & 3.2 & Bar rupture \\
\hline C26-15d $\mathrm{d}_{\mathrm{b}}-$ GFRP12-1.5d $\mathrm{d}_{\mathrm{b}}{ }^{1}$ & 48.8 & 7.2 & 2.3 & Bar rupture \\
\hline C26-15d $\mathrm{d}_{\mathrm{b}}$-GFRP10-1.5d $\mathrm{d}_{\mathrm{b}}$ & 58.2 & 12.4 & 3.7 & Bar rupture \\
\hline C26-15d $\mathrm{d}_{\mathrm{b}}$-GFRP10-1.8d $\mathrm{d}_{\mathrm{b}}$ & 54.7 & 11.6 & 5.5 & Bar rupture \\
\hline C26-15d $\mathrm{d}_{\mathrm{b}}-\mathrm{CFRP} 10-1.5 \mathrm{~d}_{\mathrm{b}}$ & 56.2 & 11.9 & 1.6 & Bar pull-out \\
\hline C25-10d $\mathrm{d}_{\mathrm{b}}$-GFRP12-1.5d $\mathrm{d}_{\mathrm{b}}$ & 36.3 & 8.0 & 1.9 & Bar pull-out \\
\hline C25-10d $d_{b}-C F R P 12-1.5 d_{b}$ & 49.6 & 11.0 & 1.5 & Bar pull-out \\
\hline C $25-5 \mathrm{~d}_{\mathrm{b}}-$ GFRP $12-1.5 \mathrm{~d}_{\mathrm{b}}{ }^{2}$ & 22.8 & 10.1 & 1.4 & Bar pull-out \\
\hline C25-5d $d_{b}-G F R P 12-1.5 d_{b}{ }^{2}$ & 27.1 & 12.0 & 2.1 & Bar pull-out \\
\hline C $25-5 d_{b}-C F R P 12-1.5 d_{b}{ }^{3}$ & 31.6 & 14.0 & 1.0 & Bar pull-out \\
\hline C $25-5 d_{b}-C F R P 12-1.5 d_{b}{ }^{3}$ & 30.1 & 13.3 & 1.2 & Bar pull-out \\
\hline C $46-15 \mathrm{~d}_{\mathrm{b}}$-GFRP10-1.5d $\mathrm{d}_{\mathrm{b}}$ & 61.2 & 13.0 & 4.7 & Bar rupture \\
\hline C46-15d $\mathrm{d}_{\mathrm{b}}$-CFRP10-1.5d & 74.8 & 15.9 & 2.2 & Bar pull-out \\
\hline C46-10d $\mathrm{d}_{\mathrm{b}}-$ GFRP10-1.5d $\mathrm{d}_{\mathrm{b}}$ & 40.4 & 12.9 & 2.8 & Bar pull-out \\
\hline C46-10d $\mathrm{d}_{\mathrm{b}}$-CFRP10-1.5d & 43.5 & 13.8 & 1.2 & Bar pull-out \\
\hline C $46-5 d_{b}-G F R P 10-1.5 d_{b}$ & 21.6 & 13.8 & 1.7 & Bar pull-out \\
\hline C $46-5 d_{b}-C F R P 10-1.5 d_{b}$ & 21.1 & 13.4 & 1.1 & Bar pull-out \\
\hline
\end{tabular}




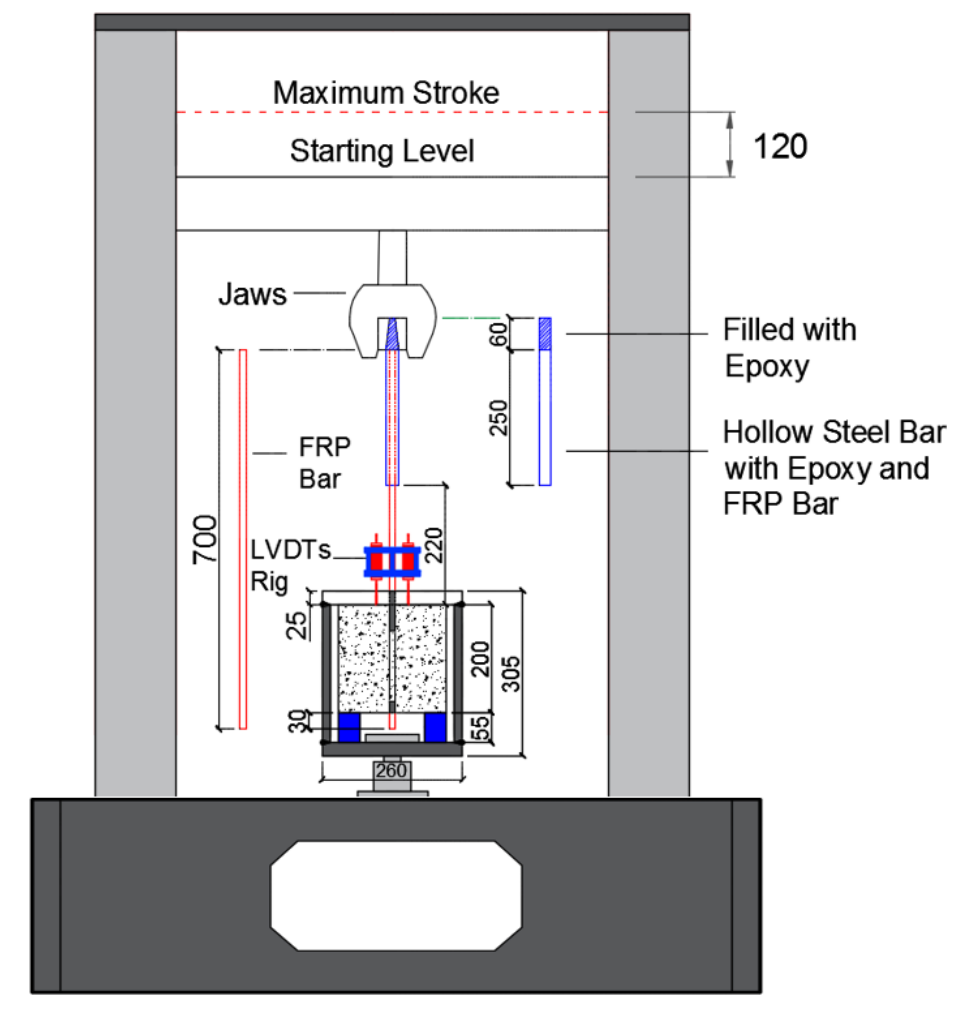

(a)

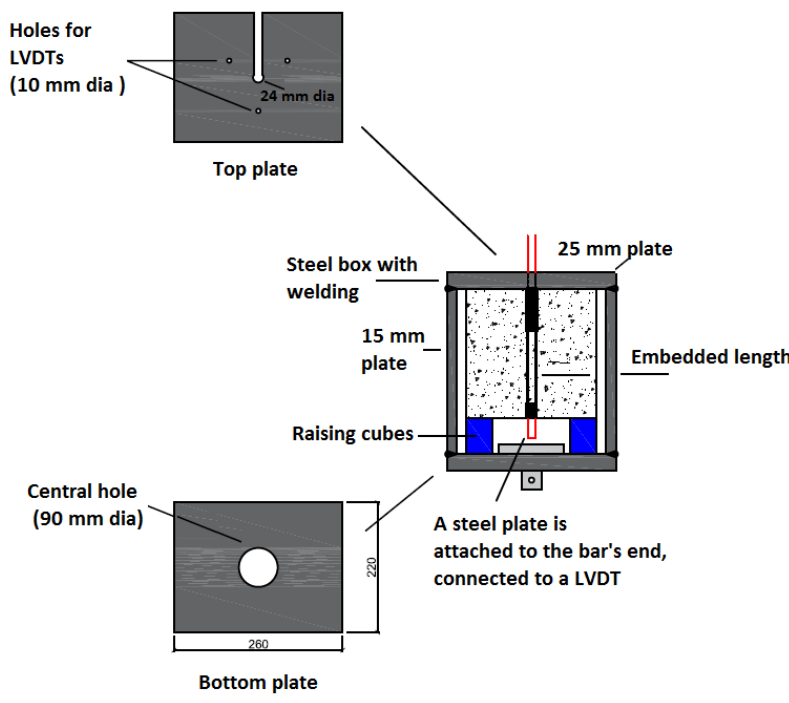

(b)

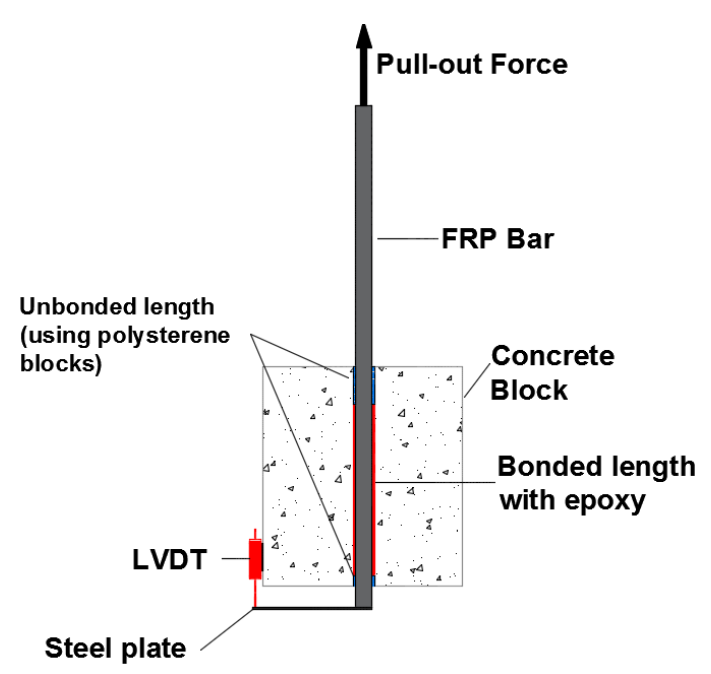

(c)

Figure 1. Test details (all dimensions in mm): (a) test setup, (b) steel box and (c) test specimen 


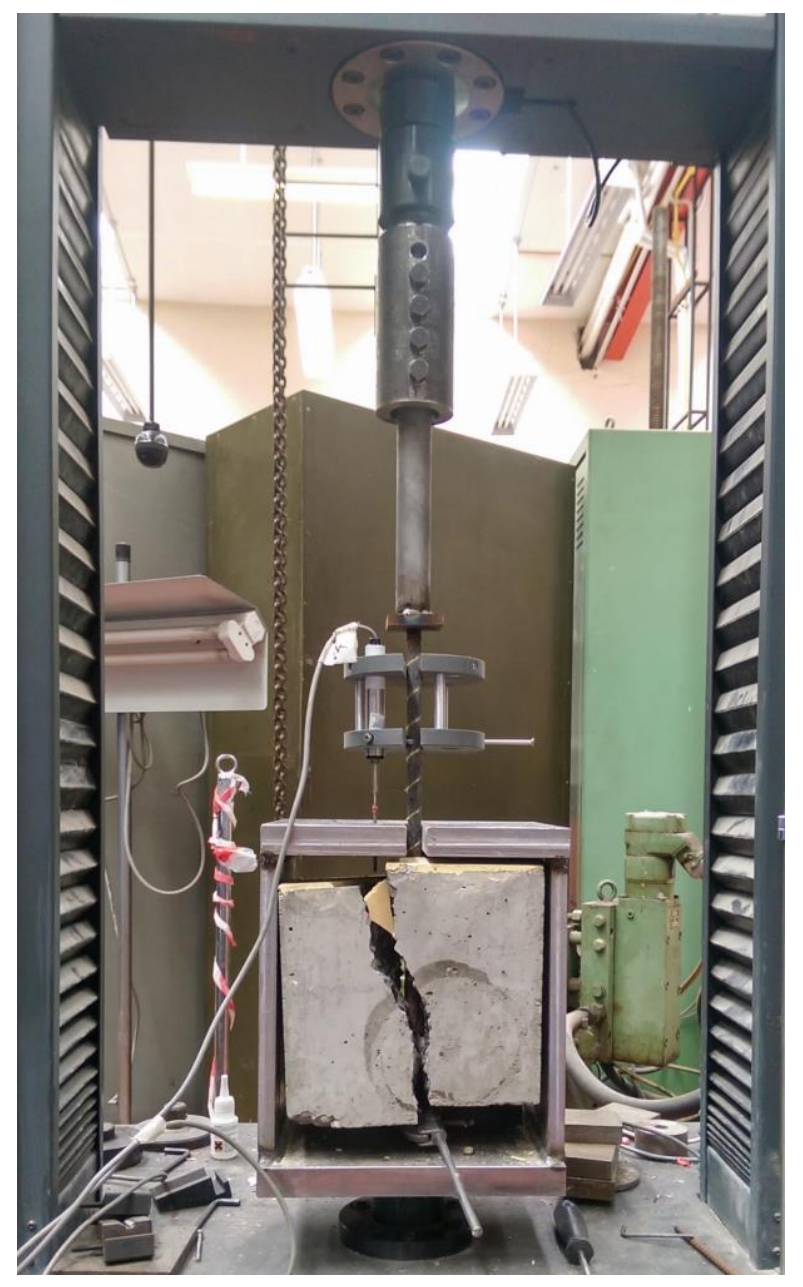

(a)

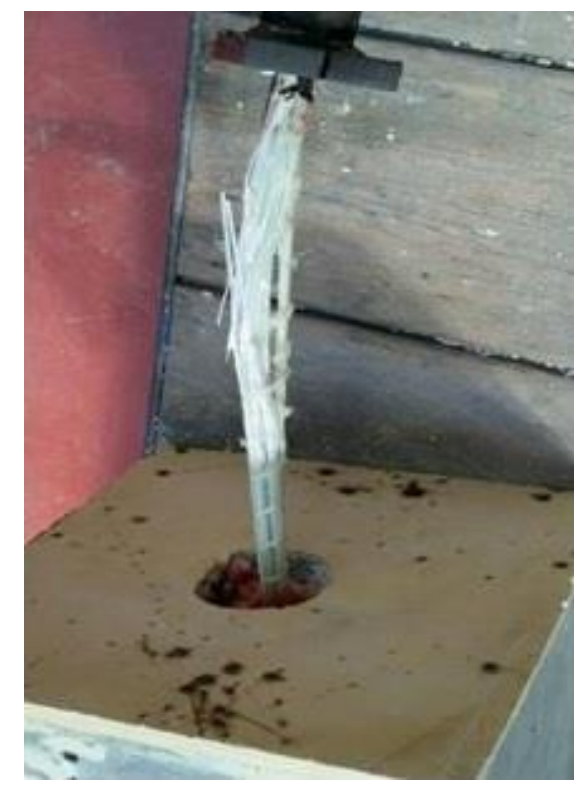

(b)

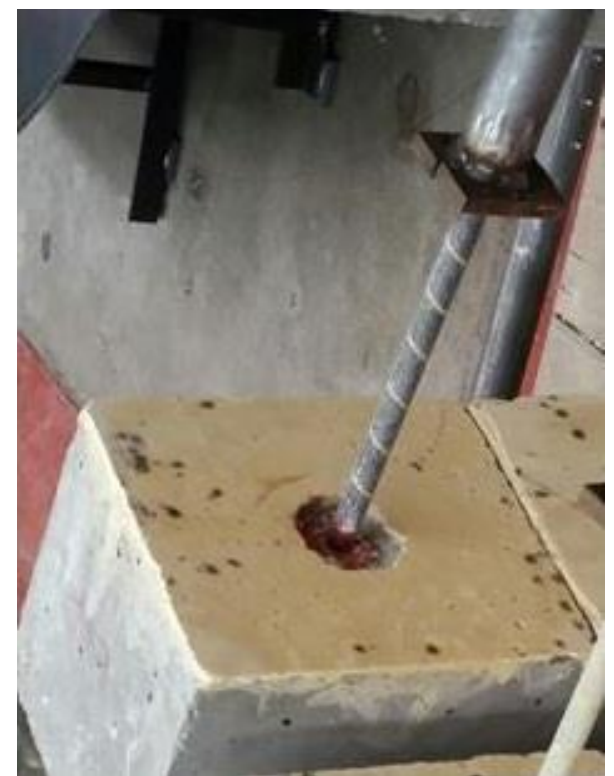

(c)

Figure 2. Failure modes: (a) concrete splitting, (b) bar rupture and (c) bar pull-out 


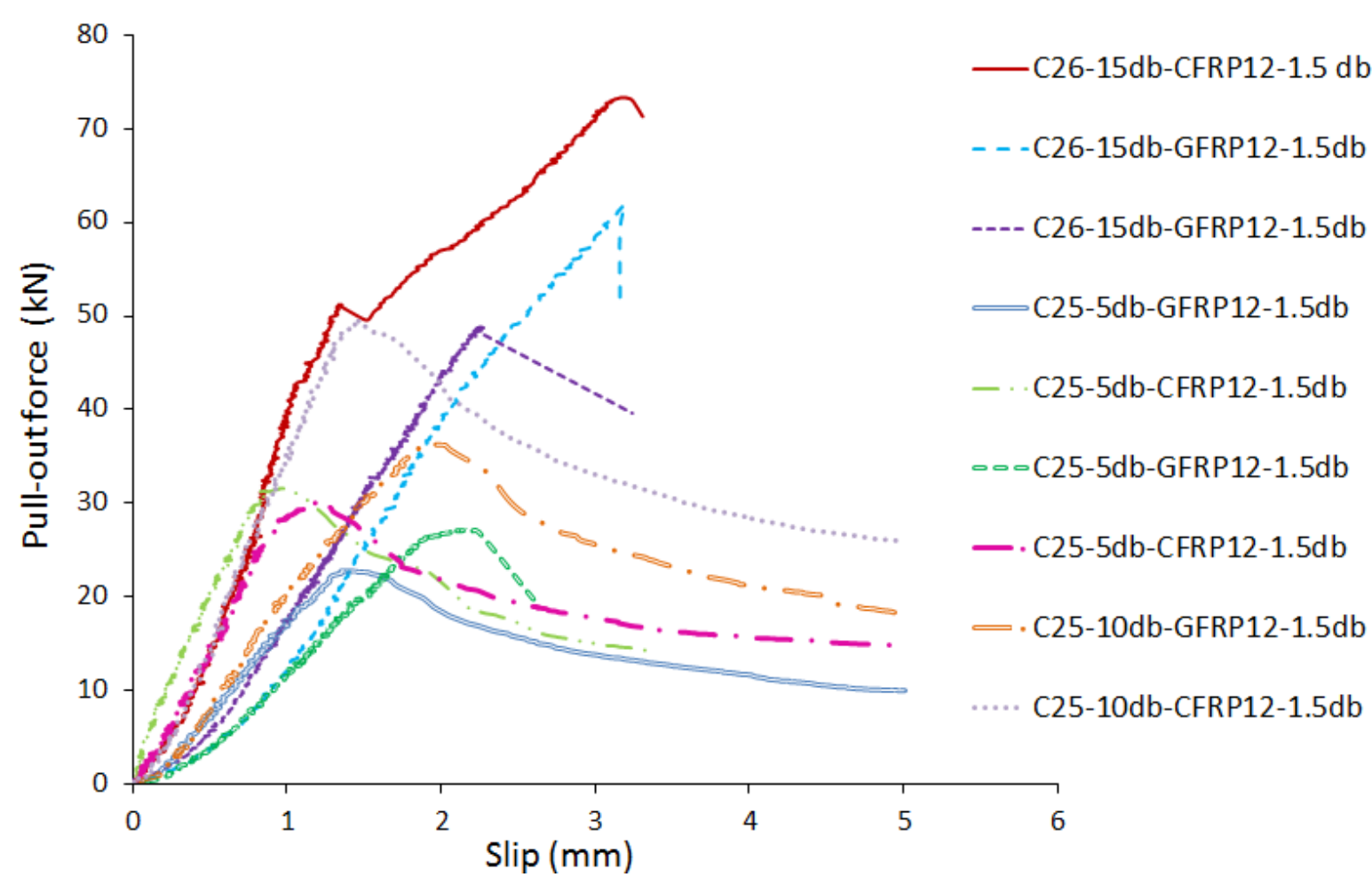

(a)

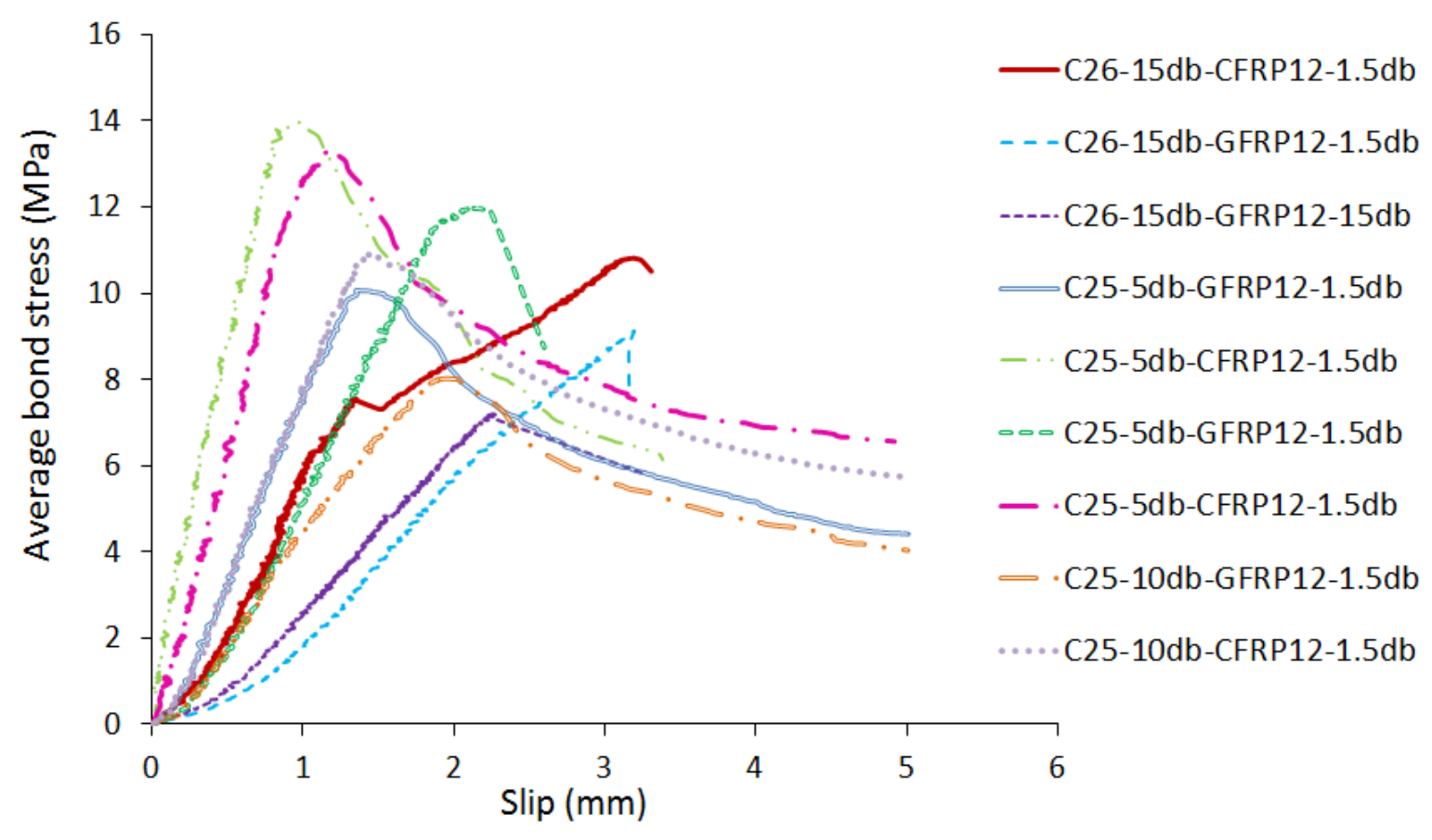

(b)

Figure 3. Bond-slip curves for the specimens with $12 \mathrm{~mm}$ FRP bars: (a) pull-out forceslip curves and (b) average bond stress-slip curves 


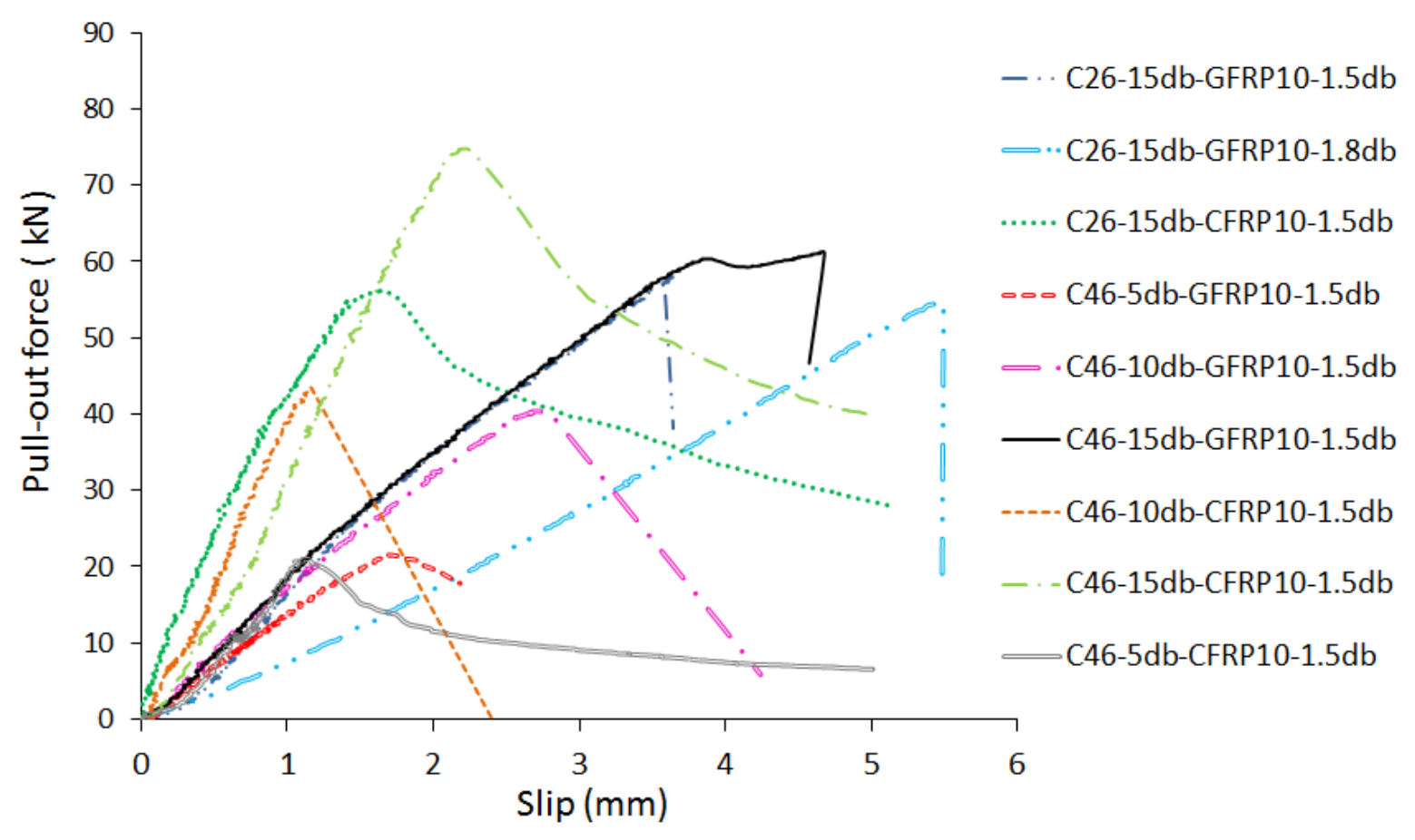

(a)

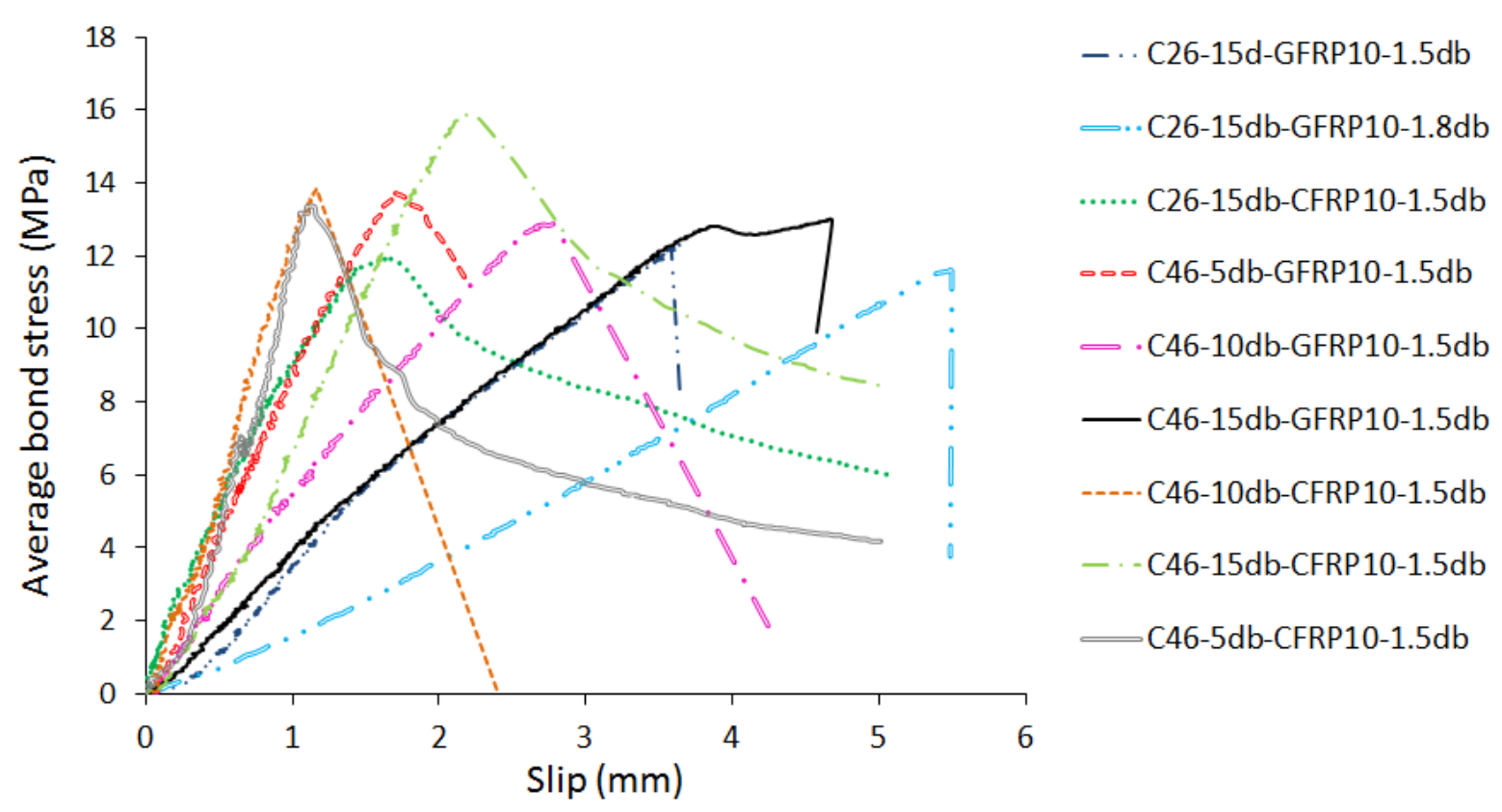

(b)

Figure 4. Bond-slip curves for the specimens with $10 \mathrm{~mm}$ FRP bars: (a) pull-out forceslip curves and (b) average bond stress-slip curves 


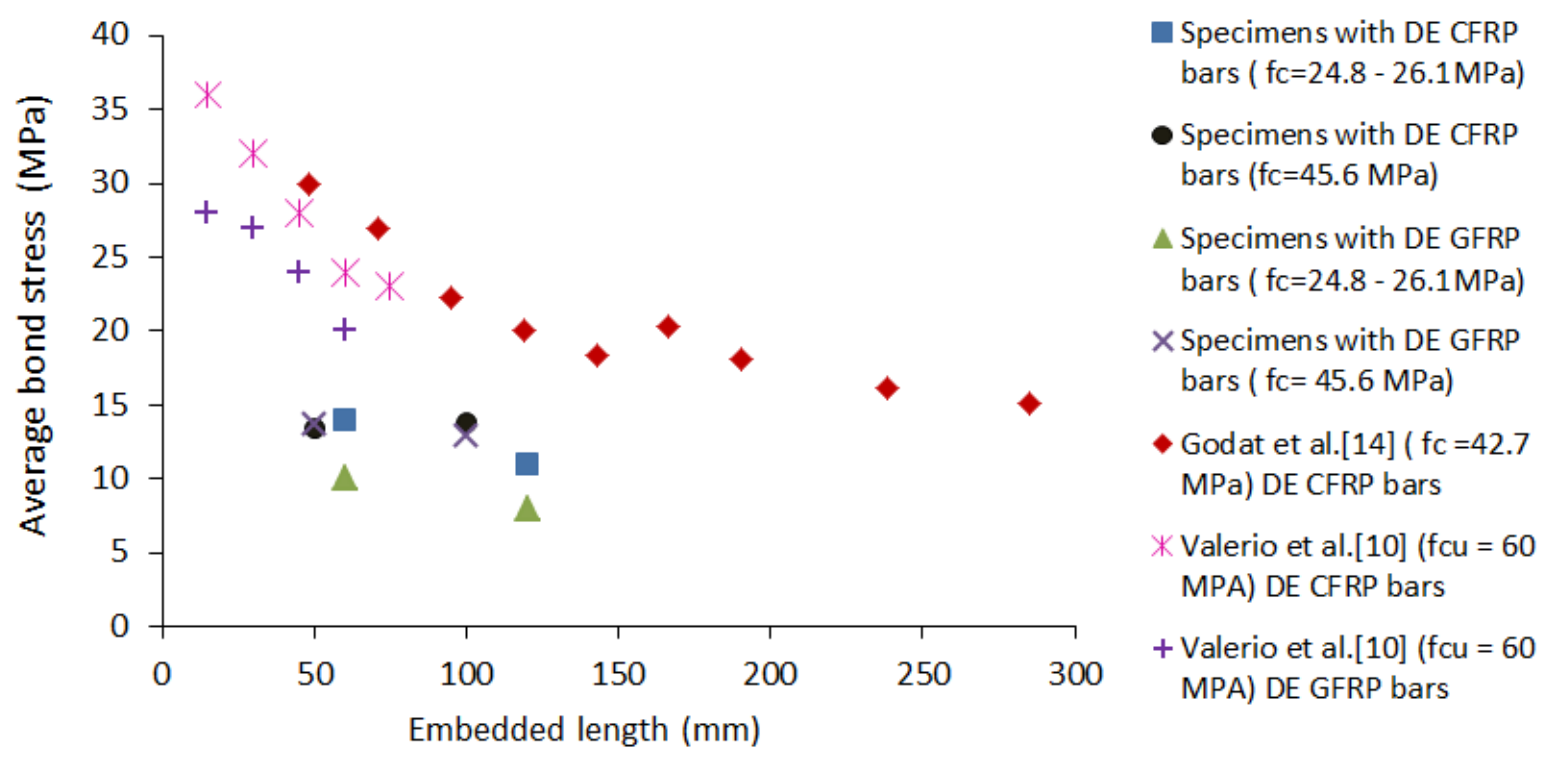

Figure 5. Effect of embedment length on maximum average bond stress

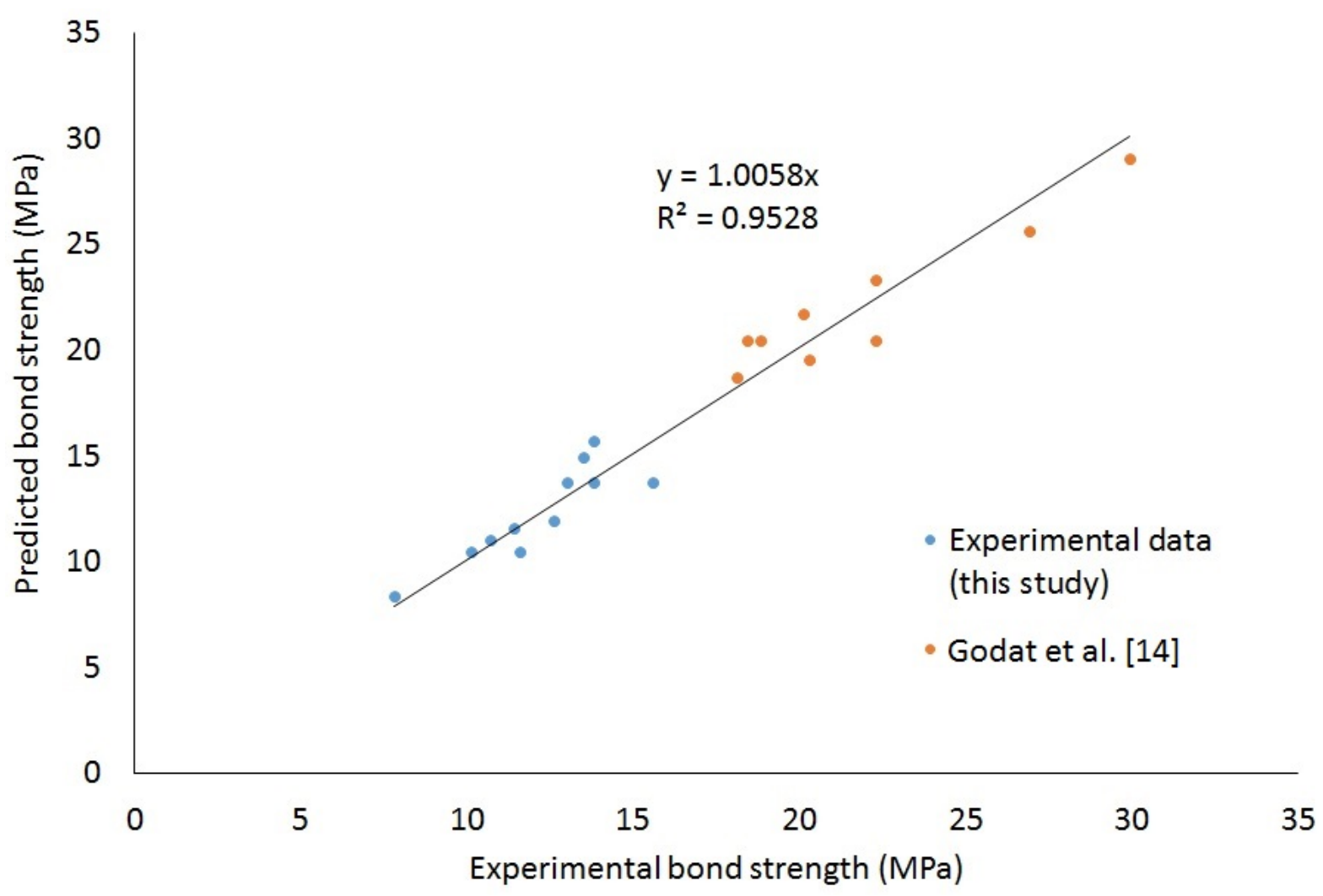

Figure 6. Model calibration - comparison between predicted and measured values 


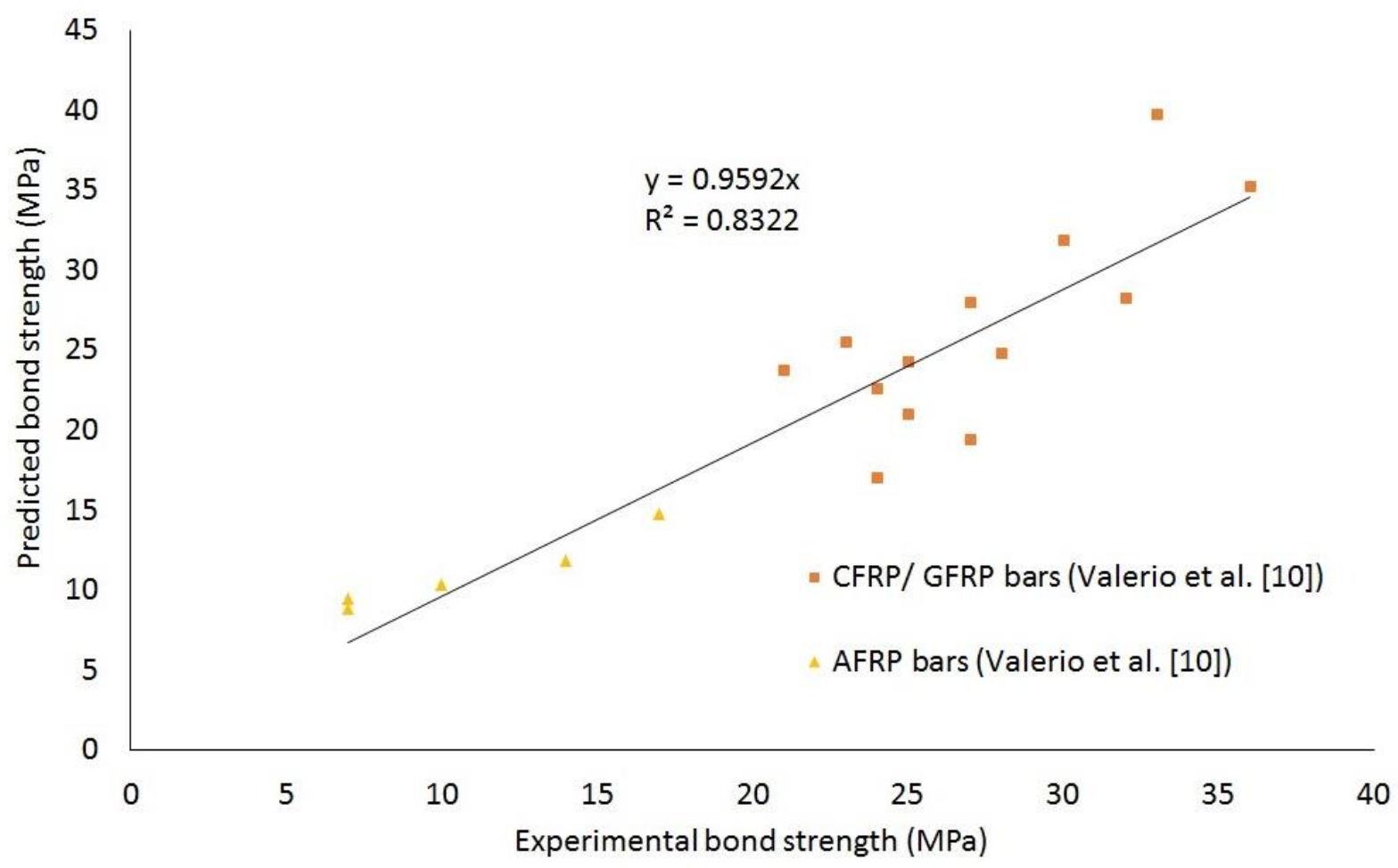

Figure 7. Model validation - comparison between predicted and measured values 